\title{
Characterization of drop-casted graphene/cellulose thin film on printing paper substrate
}

\author{
Amirul Hadi Azmi, Shaharin Fadzli Abd Rahman, Mastura Shafinaz Zainal Abidin \\ School of Electrical Engineering, Faculty of Engineering, Universiti Teknologi Malaysia, Malaysia
}

\begin{tabular}{l} 
Article Info \\
\hline Article history: \\
Received Jan 5, 2020 \\
Revised Feb 13, 2020 \\
Accepted Mar 9, 2020 \\
\hline
\end{tabular}

Keywords:

Conductive ink

Graphene

Microcrystalline cellulose

Paper electronics

\begin{abstract}
Paper electronics is an emerging technology to implement flexible and wearable electronics devices via ink printing process. This paper evaluates the feasibility of using conventional printing paper for coating process with graphene/cellulose ink. 4 different types of regularly used conventional printing papers were used as substrates in this work. The conductive graphene ink was prepared through exfoliation of graphite in cellulose solution. The paper substrates surface morphology and sheet resistance of the drop-casted conductive ink on each paper were analyzed and discussed. Glossy paper was found to be suitable paper substrate for the printing of the formulated ink due to its low surface roughness of $16 \mathrm{~nm}$. The value of sheet resistance of the graphene/cellulose thin film can be lowered to $4.11 \mathrm{k} \Omega / \mathrm{sq}$ by applying multiple drops. This work suggests that conventional printing paper may offer solution for highly scalable and low-cost paper electronics.
\end{abstract}

Copyright $\odot 2020$ Institute of Advanced Engineering and Science. All rights reserved.

\section{Corresponding Author:}

Shaharin Fadzli Abd Rahman,

School of Electrical Engineering,

Faculty of Engineering,

Universiti Teknologi Malaysia, Malaysia.

Email: shaharinfadzli@utm.my

\section{INTRODUCTION}

Paper electronic is regarded as an innovative approach for the implementation of flexible, wearable and disposable electronic devices. In comparison with other flexible substrates such as polyimide, polyethylene terephthalate (PET) and polyethylene naphthalene (PEN), paper substrate is inexpensive, bio-degradable, and renewable. Furthermore, the environmental friendly paper substrate can be fabricated from agricultural wastes and residues. In recent years, the possibility of using paper as a substrate for electronics application has received a great deal of attention mainly due to the paper's flexibility, low cost, and its long history as a material that people are familiar with [1-4]. The low-cost and recyclable paper substrates have been considered for various novel and value-added printed electronic applications [5-9]. The demonstrated applications include transistor [10-11], supercapacitors [12-13], sensors [14], actuators [15], biomedical devices [16-17], foldable thermochromics displays [18] and photovoltaic devices [19-20].

Paper substrate and conductive ink are two important materials in the fabrication process of the printed paper electronics. Different type of paper will have different degree of surface roughness, porosity, and wettability. In general, paper with low surface roughness is favorable as it can facilitate the deposition of high quality conductive and semiconducting thin film. The wettability and surface energy of the paper substrate also need to be taken into account to ensure the designed pattern is properly printed on the substrate surface. The wettability is also related to the conductive ink properties, namely surface tension. The modification of the ink surface tension is done during the ink formulation process. During the ink formulation process, the coductivty value of the conductive ink is also adjusted.

This work focuses on utilizing cellulose solution-based graphene ink as the conductive ink for the printed paper electronics. Although the usage of cellulose as additive in formulating conductive ink is widely 
presented, the study on so-called 'cellulose solution' as the solvent of the conductive ink is still limited. The cellulose solution is made from crystalline cellulose and sodium hydroxide aqueous solution. In comparison to high performance solvent such as N-methyl-2-pyrrolidone (NMP) and dimethylformamide (DMF), cellulose solution is less toxic and inexpensive. E. S. Ferreira et la. have successfully demonstrated the preparation of cellulose solution-based graphene ink via simple process. Cellulose solution was found to be effective in exfoliating graphite and stabilizing the graphene in the aqueous solution [21-22]. However, the work did not discuss the suitability of the conductive ink for printed paper electronics.

This paper presents our preliminary works on preparation of cellulose solution-based graphene ink and its application on different type of common printing paper. The conventional printing paper offers cheaper alternative to the research-grade paper substrate. For preparation of graphene ink, procedure presented by E. S. Ferrerira was modified. Some modification on cellulose concentration and exfoliation process was required to obtain a satisfactory result. This paper shall provide alternative procedure for preparation of cellulose solution-based graphene ink. In order to investigate the printing suitability of the ink onto different type of printing paper, small amount of the conductive ink was drop-casted on the paper. The morphology of ink pattern and sheet resistance were analyzed and discussed. Based on the obtained results, the suitability of the aforementioned printing paper is evaluated.

\section{RESEARCH METHOD}

Four different papers used in this work are Plain Paper 800 gsm (Double A brand), Plain Paper 800 gsm (Paper One Brand), Matte paper 230 gsm (Kodak brand) and Glossy paper 150 gsm (Fullmark brand). These paper substrates were characterized using Atomic Force Microscopy (AFM) to identify its surface roughness. Surface roughness analysis is crucial in this work as it will affect the spread and wettability of ink.

Conductive ink was prepared using the procedure shown in Figure 1. The conductive ink was obtained by adding partially exfoliated graphite into cellulose solution. Partially exfoliated graphene was obtained by exfoliating expandable graphite under $800 \mathrm{~W}$ microwave for $40 \mathrm{~s}$ [22]. The microwave treatment resulted in increase of overall volume of graphite flakes due to the exfoliation. Then, the exfoliated graphite was washed using excessive deionized water (DI) water until the PH of the graphite became 7 [23]. The washed graphite was dried in the oven at $100{ }^{\circ} \mathrm{C}$ for 2 hours.

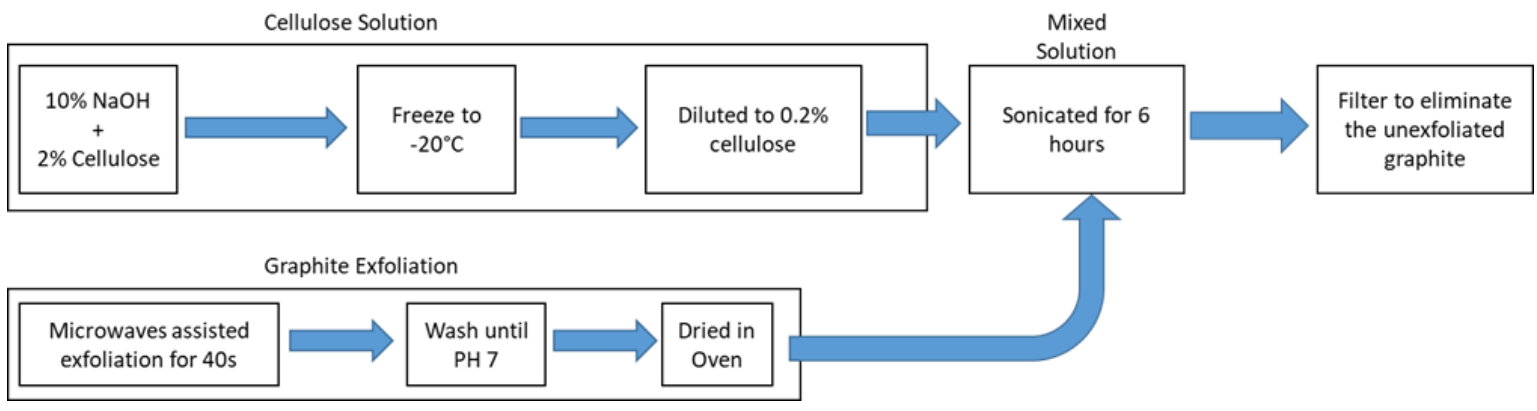

Figure 1. Process flow of graphene/cellulose ink preparation

Cellulose solution was prepared using Kamide's procedure [24]. The cellulose solution was prepared by dispersing $1.13 \mathrm{~g}$ microcrystalline cellulose powder in $50 \mathrm{ml} 10 \%$ aqueous sodium hydroxide $(\mathrm{NaOH})$ solutions. The resulted concentration of cellulose was $2 \%$. The mixture was stirred for 10 min at $1500 \mathrm{rpm}$ using magnetic stirrer and cooled down to $-20^{\circ} \mathrm{C}$ until it became a solid frozen mass. The frozen mass was allowed to thaw at room temperature. The cellulose solution was further diluted using $5 \% \mathrm{NaOH}$ solution to obtain $0.2 \mathrm{mg} / \mathrm{ml}$ cellulose concentration with gentle shaking [25]. A clear cellulose solution was obtained. $0.2 \mathrm{mg} / \mathrm{ml}$ cellulose concentration is essential to maximize graphene concentration and enhanced stability in the resulting dispersions [21].

The partially exfoliated graphite was added into the prepared cellulose solution with graphite-tocellulose ratio of 20:1. Cellulose acts as an agent for the exfoliation process. However, our preliminary experiment showed that too much cellulose could reduce the conductivity of the graphene. Therefore, high graphite-to-cellulose ratio is preferable. The mixture was sonicated inside ultrasonic bath for $8 \mathrm{~h}$. In the final process of ink preparation, large sized of unexfoliated graphite particle was filtered from the sonicated solution using metal mesh. 
20 ul graphene ink was drop-casted on the aforementioned four paper substrates. After dried in room temperature, the sheet resistance $\left(\mathrm{R}_{\text {sheet }}\right)$ was measured using 4 point-probe configuration. Microscope image was taken to analyze the morphology of the graphene film and the ink spreading.

\section{RESULTS AND ANALYSIS}

Figure 2(a)-(d) shows AFM height images of the surface of the investigated paper substrate. Height profiles between two random points in each AFM image are shown in Figure 2(e)-(h). General printing paper (i.e. Paper One and Double A) and matte paper have wavy surface compare with the glossy paper. Based on the height profiles, the height difference between the peak and valley for the papers was several micrometers. The wavy surface of general printing paper is associated to the paper fibers size. On the other hand, the height difference between peak and valley in the height profile was around $0.12 \mu \mathrm{m}$. Matte and glossy paper are polymer-coated papers. The presence of a polymer coating on Glossy and Matte paper minimizes the surface roughness. Matter paper is designed to have rougher surface in order to reduce glare. Glossy paper shows the lowest average roughness at $16.02 \mathrm{~nm}$. Thus, it is expected to provide flat surface for deposition of more uniform conductive thin film.

Surface morphology of the drop-casted graphene film on the different paper substrates is shown in Figure 3. Drop-casting onto glossy paper produced more uniform graphene thin film with sharp end edge. The magnified microscope image showed that most of the paper surface was covered by the conductive ink. The uniform distribution of graphene/cellulose ink on the glossy paper might be due to the low surface roughness of the substrate. Uniform thin film is important to ensure good conductivity value. In case of other substrates, in particular to 'Double A' paper as shown in Figure 3(a), the deposited particles are not connected with each other. This should lead to poor electrical conduction across the graphene thin film.

Interestingly, despite of high surface roughness, graphene film on Paper One show in Figure 3(b) relatively uniform coating. Other factors such as ink absorption and paper's reaction towards the ink solution needs to be considered. The formulated conductive ink consists of $\mathrm{NaOH}$ which may react to the cellulose fiber in the paper.

a)

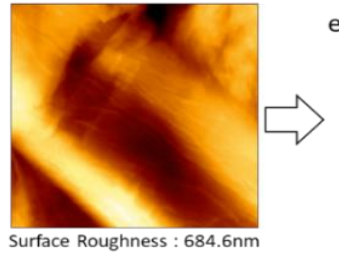

b)

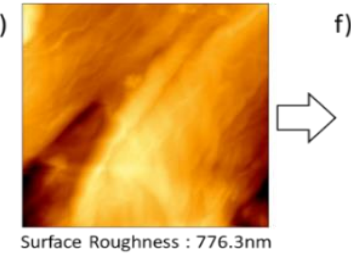

c)

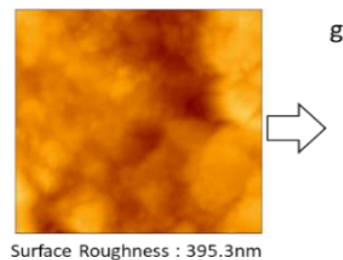

d)

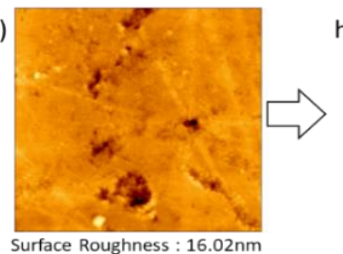

g) e)
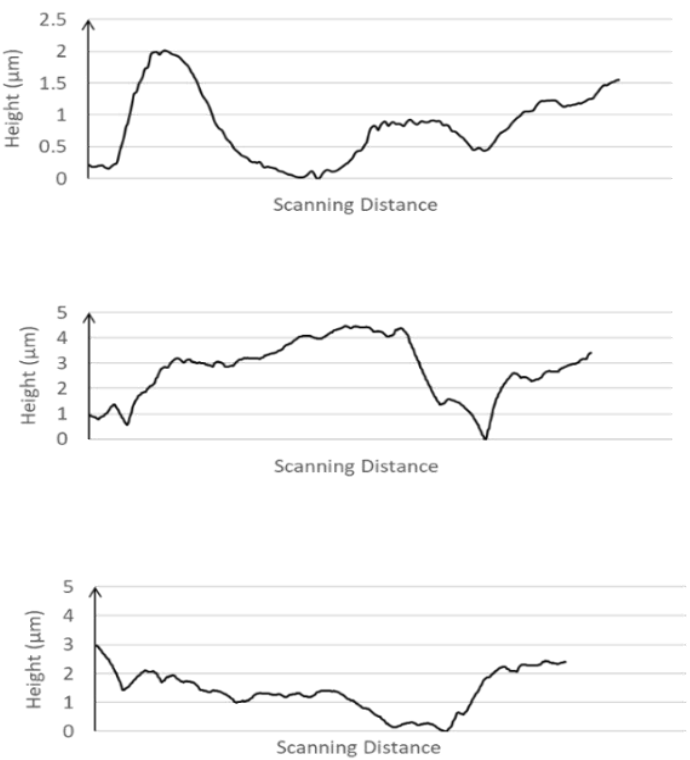

h)

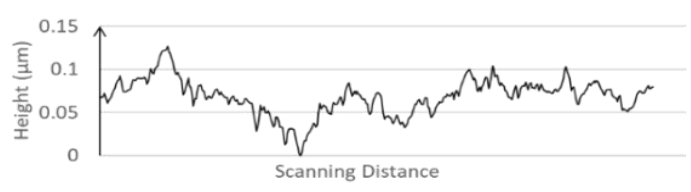

Figure 2. AFM height image of (a) Plain Paper - Double A, b) Plain Paper - Paper One, c) Matte Paper, and d) Glossy Paper and height profiles from the AFM images (e-h) 

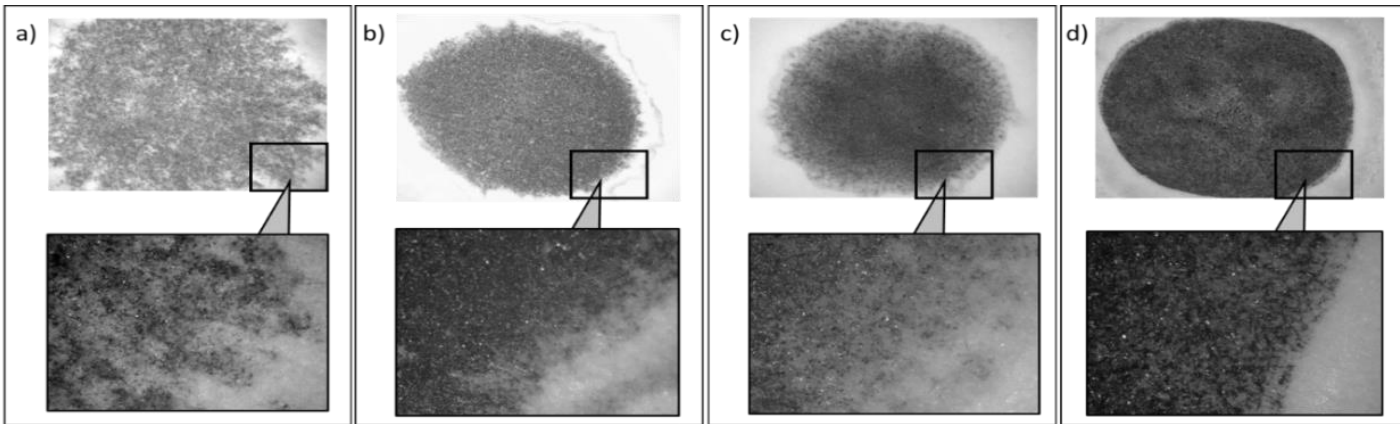

Figure 3. Microscope images of the drop-casted graphene thin film on a) Plain Paper - Double A, b) Plain Paper - Paper One, c) Matte Paper, and d) Glossy Paper

$\mathrm{R}_{\text {sheet }}$, was calculated using (1). $\mathrm{R}_{4}$ is the measured resistance value from 4 point probe measurement. $f_{2}$ is the correction factor based on ratio of probe spacing and thin film diameter. Shows in Figure 4 the calculated sheet resistance for the graphene thin film deposited on the different paper substrates. Glossy paper has the lowest sheet resistance as $7.63 \mathrm{M} \Omega /$ sq. Glossy paper with least surface roughness value tends to have least resistance value as the ink spread is uniformly formed on the paper substrates.

$$
\mathrm{R}_{\text {sheet }}=4.53 \times \mathrm{R}_{4} \times \mathrm{f}_{2}
$$

The conductivity of the graphene coating can be improved by applying multiple drop casting. Shown in Figure 5 the change in sheet resistance value after multiple drops. Resistance value decreases upon the increasing number of coating. Each drop-coating increased the number of graphene particles in the thin film. Addition of graphene particles improve the electrical connection between the particles and leads to thicker thin film. Thus, lower resistance could be achieved. After 4 times drop-casting, the sheet resistance was $4.11 \mathrm{k} \Omega / \mathrm{sq}$.

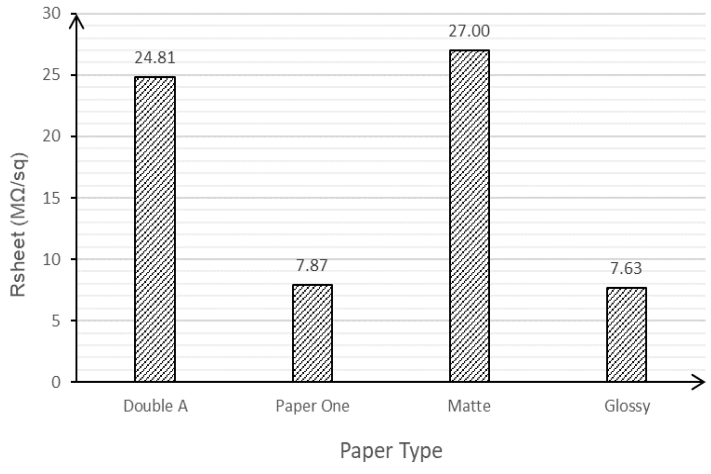

Figure 4. Sheet resistance on paper substrates

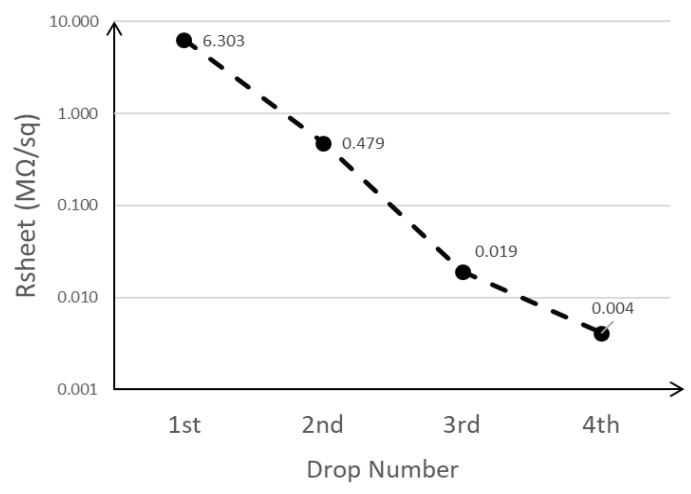

Figure 5. Sheet resistance of multi-drop of graphene ink

Conductivity, $\sigma$, of the graphene thin film was calculated using (2). $\mathrm{t}$ is thin film thickness.

$$
\sigma=\frac{1}{R_{\text {sheet }} \mathrm{t}}
$$

The thickness of graphene thin layer was measured using 3D microscope. The 3D microscope image of the film made from 4-drop ink is shown in Figure 6(a). Shows in Figure 6(b) height profile along the dashed line in the microscope image. Based on the height profile, the thickness of the film was $11.24 \mu \mathrm{m}$. The conductivity was calculated to be $21.34 \mathrm{~S} / \mathrm{m}$. The obtained value is three order lower than that reported by E.S. Ferreira. It is worth to note that method used for graphene film formation was different from the reported work. The coating procedure has effect of the coated film homogeneity and conductivity. Further analysis is required to address this matter. 

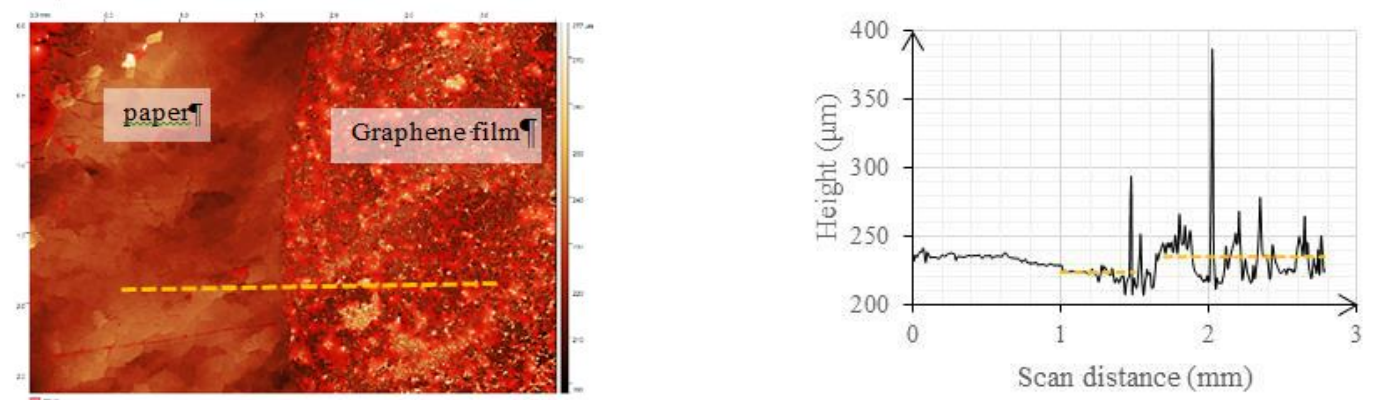

Figure 6. (a) 3D microscope image and (b) Height profile of the graphene film made from 4-drop ink

Ink that has high stability can maintain its solution form for long period. Practical ink need to have a very long period of ink stability to ensure quality. In this work, the ink was left in room-temperature condition for two days and any physical changes was observed. Shows in Figure 7 the change of ink after certain time. After 6 hours, graphene/cellulose particle settled at the bottom of the test tube. The formulated ink was not stable as expected. Further improvement in ink formulation is required. Nevertheless, this unstable ink can be dissolved again with just a gentle shake.

a)

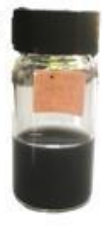

b)

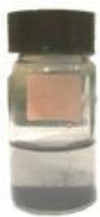

c)

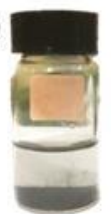

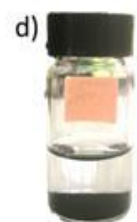

Figure 7. Graphene ink stability. a) Initial stages, b) after 6 hours, c) after 18 hours, d) after 36 hours

\section{CONCLUSION}

In conclusion, the effect of substrates paper to the sheet resistance of the drop-casted graphene/cellulose thin film was investigated. Glossy paper was found to be suitable paper substrate for printing the formulated conductive ink. The ink drop-casted on the glossy paper showed better uniformity. As expected, the graphene/cellulose thin film on glossy paper showed the lowest sheet resistance. The value of sheet resistance can be lowered to $4.11 \mathrm{k} \Omega / \mathrm{sq}$ by applying multiple drops. The obtained graphene film has conductivity of $21.34 \mathrm{~S} / \mathrm{m}$. The results of this work implies the feasibility of using relatively low-cost of paper substrate for fabricating paper electronic devices.

\section{ACKNOWLEDGEMENTS}

This work was supported by Universiti Teknologi Malaysia research university grant (06G89 and 16J02). A. H. Azmi is Graduate Research Assistant under research university grant (06G89).

\section{REFERENCES}

[1] S. M. Lyth and S. R. P. Silva, "Field emission from multiwall carbon nanotubes on paper substrates," Appl. Phys. Lett., vol. 90, no. 17, pp. 2007-2009, 2007, doi: 10.1063/1.2734379.

[2] F. Eder, H. Klauk, M. Halik, U. Zschieschang, G. Schmid, and C. Dehm, "Organic electronics on paper," Appl. Phys. Lett., vol. 84, no. 14, pp. 2673-2675, 2004, doi: 10.1063/1.1690870.

[3] S. Lim, J. Lin, Y. Zhu, C. Sow, and W. ji, "Synthesis, characterizations, and field emission studies of crystalline Na2V6O16 nanobelt paper,” J. Appl. Phys., vol. 100, p. 16105, Jul. 2006, doi: 10.1063/1.2213186.

[4] Y.-H. Kim, D.-G. Moon, and J.-I. Han, "Organic TFT array on a paper substrate," IEEE Electron Device Lett., vol. 25, no. 10, pp. 702-704, 2004, doi: 10.1109/LED.2004.836502.

[5] D. Tobjörk and R. Österbacka, "Paper Electronics,” Adv. Mater., pp. 1935-1961, 2011, doi: 10.1002/adma.201004692.

[6] P. Przybysz, "E-paper-potential competitor of printing papers," Ann. Warsaw Agric. Univ. For. Wood Technol., no. 59, 2006. 
[7] N. D. Robinson and M. Berggren, "Printing organic electronics on flexible substrates," 2007.

[8] B. Trnovec et al., "Coated Paper for Printed Electronics," pp. 48-51, 2009.

[9] A. C. Siegel, S. T. Phillips, J. Wiley, and G. M. Whitesides, "Thin, lightweight, foldable thermochromic displays on paper $\dagger$," vol. 9, no. 19, 2009, doi: 10.1039/b905832j.

[10] E. Fortunato, N. Correia, P. Barquinha, L. Pereira, G. Goncalves, and R. Martins, "High-Performance Flexible Hybrid Field-Effect Transistors Based on Cellulose Fiber Paper," IEEE Electron Device Lett., vol. 29, no. 9, pp. 988-990, 2008, doi: 10.1109/LED.2008.2001549.

[11] W. H. Yeo et al., "Multifunctional epidermal electronics printed directly onto the skin," Adv. Mater., vol. 25, no. 20, pp. 2773-2778, 2013, doi: 10.1002/adma.201204426.

[12] Y. Z. Zhang, Y. Wang, T. Cheng, W. Y. Lai, H. Pang, and W. Huang, "Flexible supercapacitors based on paper substrates: a new paradigm for low-cost energy storage," Chem. Soc. Rev., vol. 44, no. 15, pp. 5181-5199, 2015, doi: $10.1039 / \mathrm{c} 5 \mathrm{cs} 00174 \mathrm{a}$.

[13] Z. Weng, Y. Su, D.-W. Wang, F. Li, J. Du, and H.-M. Cheng, "Graphene-Cellulose Paper Flexible Supercapacitors," Adv. Energy Mater., vol. 1, no. 5, pp. 917-922, Oct. 2011, doi: 10.1002/aenm.201100312.

[14] D. D. Liana, B. Raguse, J. J. Gooding, and E. Chow, "Recent Advances in Paper-Based Sensors," pp. 1150511526, 2012, doi: 10.3390/s120911505.

[15] M. Amjadi and M. Sitti, "High-Performance Multiresponsive Paper Actuators," ACS Nano, vol. 10, no. 11, pp. 10202-10210, Nov. 2016, doi: 10.1021/acsnano.6b05545.

[16] H. Shafiee et al., "Paper and flexible substrates as materials for biosensing platforms to detect multiple biotargets," Sci. Rep., vol. 5, no. i, pp. 1-9, 2015, doi: 10.1038/srep08719.

[17] K. Nagashima, H. Koga, U. Celano, F. Zhuge, M. Kanai, and S. Rahong, "Cellulose Nanofiber Paper as an Ultra Flexible Nonvolatile Memory," pp. 1-7, 2014, doi: 10.1038/srep05532.

[18] P. Andersson, R. Forchheimer, P. Tehrani, and M. Berggren, "Printable all-organic electrochromic active-matrix displays," Adv. Funct. Mater., vol. 17, no. 16, pp. 3074-3082, 2007.

[19] A. Hübler et al., "Printed paper photovoltaic cells," Adv. Energy Mater., vol. 1, no. 6, pp. 1018-1022, 2011.

[20] M. C. Barr et al., "Direct Monolithic Integration of Organic Photovoltaic Circuits on Unmodifi ed Paper," Adv. Energy Mater., no. i, pp. 3500-3505, 2011, doi: 10.1002/adma.201101263.

[21] M. Borghei et al., "High-concentration aqueous dispersions of graphene produced by exfoliation of graphite using cellulose nanocrystals," vol. 0, pp. 3-9, 2014, doi: 10.1016/j.carbon.2013.12.086.

[22] E. S. Ferreira, "Graphite exfoliation in cellulose solutions," Nanoscale, vol. 9, pp. 10219-10226, 2017, doi: $10.1039 / \mathrm{c} 7 \mathrm{nr} 02365 \mathrm{k}$.

[23] K. Pan et al., "Sustainable production of highly conductive multilayer graphene ink for wireless connectivity and IoT applications," Nat. Commun., vol. 9, no. 1, 2018, doi: 10.1038/s41467-018-07632-w.

[24] K. Kamide and K. Okajima, "Cellulose dope, process for preparation and method for application thereof," US pat, vol. 4634470, 1987.

[25] A. Isogai, L. Science, R. H. Atalla, and F. Service, "Dissolution of cellulose in aqueous NaOH solutions," pp. 309-319, 1998.

\section{BIOGRAPHIES OF AUTHORS}

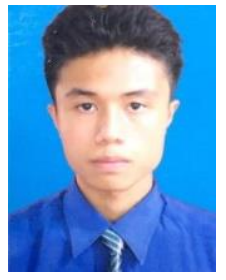

Amirul Hadi Azmi is now a postgraduate student (Master of Philosophy) in the School of Electrical Engineering, Faculty of Engineering, Universiti Teknologi Malaysia, Malaysia. He has completed his Bachelor of Engineering (Electrical) from Universiti Teknologi Malaysia, Malaysia at 2015. His research mainly focuses on fabrication of graphene-based electronics on paper susbtrate.

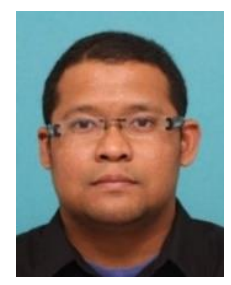

Shaharin Fadzli Abd Rahman is a senior lecturer in School of Electrical Engineering, Faculty of Engineering, Universiti Teknologi Malaysia, Malaysia. He completed his Bachelor of Engineering degree and Master of Engineering from Hokkaido University, Japan in 2007 and 2009, respectively. In 2013, he obtained Doctor of Philosophy in Electrical Engineering from Universiti Teknologi Malaysia, Malaysia. His research interest is semiconductor and graphenebased electronic device and sensor fabrication and characterization.

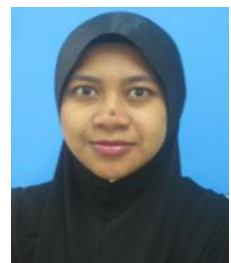

Mastura Shafinaz Zainal Abidin is a senior lecturer in School of Electrical Engineering, Faculty of Engineering, Universiti Teknologi Malaysia, Malaysia. She completed her Bachelor of Engineering degree and Master of Engineering from Universiti Teknologi Malaysia, Malaysia, in 2008 and 2010, respectively. She obtained Doctor of Philosophy in Electrical Engineering also from Universiti Teknologi Malaysia, Malaysia. Her research interest is material growth, fabrication and characterization of semiconductor devices, compound semiconductor sensing devices, semiconductor nanostructures and thin films. 